\title{
Alguns conceitos da teoria bakhtiniana do discurso e o ensino de literatura
}

Mayra Pinto ${ }^{a}$

\begin{abstract}
Resumo
Este artigo - parte do projeto de pós-dou torado Uma abordagem teórico-metodológica bakhtiniana do acervo literário do Programa Nacional Biblioteca da Escola (PNBE)/2013 para o ensino médio - procura demonstrar a pertinência de alguns conceitos da teoria bakhtiniana do discurso para o ensino de literatura. No trabalho com literatura em sala de aula, se quisermos enfrentar os males da sua escolarização inadequada (SOARES, 2011, p.?), é importante compreender conceitos como dialogismo, que contribui para abordar as diferentes camadas estilísticas e axiológicas próprias dos discursos artísticos em geral, não só do literário. Trabalhar didaticamente com a noção da "construção dialógica" do discurso literário significa poder formar um leitor que percebe os matizes polissêmicos do texto, que pode construir interpretações sobre ele de acordo com sua visão de mundo e seus conhecimentos, que pode fazer com certa segurança apreciações "estéticas e/ou afetivas" e elaborar "apreciações relativas a valores éticos e/ou politicos" (ROJO, 2004, p.?). Sob a perspectiva bakhtiniana, entende-se que a comunicação se dá por meio do enunciado concreto que compreende duas partes: a parte percebida ou realizada em palavras e a parte presumida - o horizonte espacial e ideacional compartilhado pelos falantes; sua característica distintiva é que estabelece uma miríade de conexões com o contexto extraverbal da vida (BAKHTIN; VOLOSHINOV, 1976, p.?). A compreensão do conceito de enunciado concreto contribui para que o professor perceba a questão da ideologia sob o ponto de vista bakhtiniano - tudo o que envolve a visão de mundo e sua escala de valor. Essa noção permite perceber os valores, positivos e negativos, que atravessam todos os discursos e os constituem como discursos das mais diferentes vozes sociais.
\end{abstract}

Palavras-chave: Ensino de literatura; Dialogismo; Enunciado concreto.

\footnotetext{
a Doutora em Educação pela Universidade de São Paulo. mayrapinto@uol.com.br
} 
Este artigo - parte do projeto de pós-doutorado "Uma abordagem teórico-metodológica bakhtiniana do acervo literário do Programa Nacional Biblioteca da Escola (PNBE)/2013 para o ensino médio" - procura demonstrar a pertinência de alguns conceitos da teoria bakhtiniana do discurso para o ensino de literatura.

O projeto surgiu a partir da constatação de uma série de demandas em relação ao ensino de literatura nas práticas escolares atuais. A principal delas, talvez, seja a demanda da própria comunidade escolar registrada em pesquisa analisada na publicação Programa Nacional Biblioteca da Escola (PNBE): leitura e biblioteca nas escolas públicas brasileiras (BRASIL, 2008, p. 103):

A necessidade da formação docente para trabalhar com os acervos foi apontada como aspecto central em todos os locais pesquisados, especialmente quando se pensa em política de formação de leitores, com distribuição de acervos.

Aliás, sobre isso, o documento é enfático ao reiterar em inúmeras passagens essa necessidade (BRASIL, 2008, p. 111, $124,125,128)$. Esse documento foi produzido a partir de uma pesquisa de Avaliação Diagnóstica feita em escolas públicas de todo país, para dar continuidade a uma política de formação de leitores que não se limitasse a adquirir e distribuir livros às escolas ${ }^{1}$. É, portanto, um bom parâmetro sobre o que acontece na escola brasileira quando se trata de abordar o texto literário, pelo menos nesta primeira década dos anos 2000.

De acordo com a pesquisa, os professores veem a necessidade de uma formação específica para abordar o texto literário porque reconhecem desconhecer estratégias específicas para seu tratamento didático. De um modo geral, constatou-se um "trabalho funcional com a leitura", cuja "lógica que se perce-

1 Como se sabe, o PNBE é um programa voltado para a distribuição gratuita de obras - além dos acervos de literatura, são distribuídos, em todas as escolas públicas da educação básica, acervos compostos por obras de referência, de pesquisa e de outros materiais relativos ao currículo nas áreas de conhecimento da educação básica. beu de tratamento das obras literárias deixou de valorizar o lúdico, a fantasia, a imaginação, para enformar a fruição do gênero literário nos moldes escolares." (BRASIL, 2008, p. 127). A constatação do trabalho inadequado está registrada em inúmeras passagens do documento: “Usavam-se obras de literatura como pré-textos ao ensino da gramática, da ortografia, e mesmo quando a lógica se afastava desse modelo, ainda assim apequenava a grandeza dos muitos sentidos possíveis de serem atribuídos em um texto literário. Livros clássicos de 
literatura eram desprezados por professores, considerados 'bem antigos'”' (BRASIL, 2008, p. 107-108).

Os professores reconhecem também, em suas trajetórias como leitores, condições que contribuem para entender, em parte, sua insegurança na abordagem dos textos literários:

ao narrarem suas próprias histórias de vida e de leitura, contam que também eles tiveram dificuldades de ser leitores, de ter acesso aos livros, principalmente de literatura, principalmente aqueles filhos de pais pouco escolarizados, muitas vezes não leitores e de classes populares empobrecidas.(BRASIL, 2008, p. 86).

Assim, é possível constatar que as "práticas de leitura lineares e literais" (ROJO, 2004, p. 2) que atravessam a escola brasileira hoje não são marca apenas das trajetórias dos alunos; há indicadores eloquentes que evidenciam uma formação literária precária também dos professores. ${ }^{2}$

Justamente por compreender que cada vez mais a escola deveria contemplar as classes populares que começaram a se escolarizar em massa a partir da década de 80 no Brasil, os governos em âmbito federal, estadual e municipal começaram a produzir documentos orientadores das práticas escolares nesse sentido. No caso de língua portuguesa, as práticas pedagógicas são pautadas por documentos oficiais que propõem um tratamento linguístico-discursivo dos textos - de todas as esferas, literária, científica, propagandística, de imprensa etc. - desde 1998 pelo menos, quando surgiram os Parâmetros Curriculares Nacionais (PCN). Seria de se imaginar que, passados tantos anos, essa abordagem fosse já um fato na escola pública brasileira. Entretanto, essa não é a conclusão de uma pesquisa feita em uma escola de Ensino Fundamental I e II na cidade de São Paulo para investigar, dentre outros aspectos, os processos discursivos, mais próprios de gêneros secundários, presentes em aulas de diversas disciplinas - Ciências,

2 Uma publicação recente sobre o tema é $O$ professor de português $e$ a literatura, em que Gabriela Rodella de Oliveira analisa dados de pesquisa feita com professores do ensino médio na cidade de São Paulo sobre sua formação literária. Matemática, História, Geografia, além de Língua Portuguesa (ROJO, 2006). Dentre as constatações feitas, observa-se que: ler e escrever textos eram atividades pouco frequentes - "Tudo se passa como se a escrita de textos estivesse reservada para a aprendizagem dos princípios alfabéticos e ortográficos e das regras do bem escrever" (ROJO, 2006, p. 68) -; as discussões argumentativas eram raras, raras também eram as atividades 
3 Um dos livros mais conhecidos dessa equipe, editado no Brasil, é Gêneros orais e escritos na escola, de Bernard Schneuwly et al. Tradução e organização de Roxane Rojo e Glaís Sales Cordeiro. Campinas, Mercado de Letras, 2004. de leitura e escrita, não restritas à resolução de exercícios ou à resposta pontual a questionários, que tomavam como objeto de estudo gêneros secundários como relatos históricos, poemas, letras de canção, fotos, mapas, contos, anúncios, listas, crônicas, fragmentos de romances, dentre outros.

Como conclusão da análise dos dados da pesquisa, Rojo observa que não houve inter-relação entre a voz do aluno, do professor e dos discursos presentes nos gêneros vistos em aula: "Ao contrário, o que vimos em grande parte da amostra analisada é um estilo autoritário de condução do discurso por parte do professor, que exige reconhecimento e repetição automática dos alunos" (ROJO, 2006, p.71). Rojo chama esse processo de ventriloquismo: atitude típica de uma educação autoritária que impõe, tanto ao aluno quanto ao professor, a repetição automática das vozes consagradas pelas instituições por intermédio, sobretudo, dos textos didáticos. Essa mesma crítica a uma educação engessada em parâmetros restritos à reprodução de modelos recebe vários outros nomes: "mal da escolarização" (BERENBLUM e PAIVA, 2006) "letramento serviçal" (PAULINO e COSSON, 2009), "pedagogia da facilitação" (OSAKABE, 2005). Em todas essas definiç̧ões, a crítica é sustentada pela noção de que o aluno não é formado para construir sua voz, individual e social de modo crítico e criativo, mas para reproduzir as vozes das instituições, de modo autoritário e submisso.

Independentemente do gênero, numa perspectiva discursiva, a linguagem não é neutra, como se sabe; há, em qualquer discurso, um posicionamento ideológico da enunciação demarcando seu lugar na arena de luta da palavra (BAKHTIN, 1988). Numa abordagem de texto, quando se deixa de pontuar essa relação, dialógica e, portanto, valorativa, não há abordagem discursiva. Pode ser, no melhor dos casos, uma abordagem linguístico-discursiva como aquela proposta pela equipe da Universidade de Genebra, cuja produção teórica foi bastante estudada nos últimos anos em determinados nichos das universidades brasileiras ${ }^{3}$. Para essa concepção de ensino de língua, "a ênfase maior é dada às capacidades linguístico-discursivas ligadas às formas composicionais ou ao estilo", já "A busca do sentido ou do efeito de sentido não é seu norte (nem seu forte) principal" (ROJO, 2006, p. 74). Em suma, para uma abordagem 
4 Sobre o assunto, há a tese de livre docência de Claudemir Belintane. A oralidade faz escrita na(s) infâncias(s): pesquisas e reflexões sobre a relação oralidade - escrita nos anos iniciais de escolarização. Faculdade de Educação/USP, 2011; e meu artigo "Alguns descompassos no ensino de literatura: documentos e práticas oficiais", a ser publicado no próximo número da revista $R e$ mate de Males (IEL/UNICAMP) sobre o tema literatura e ensino.

5 Há documentos oficiais que procuram dialogar com essa vertente - as Orientações Curriculares do Ensino Médio (2004 e 2006), o Guia de Livros Didáticos: PNLD 2013 (2012) e o documento Por uma política de formação de leitores (2006) são alguns exemplos. No entanto, esse diálogo parece ainda não ter ecoado em certas práticas institucionais. No momento atual, observa-se, em relação ao ensino de literatura, uma espécie de descompasso entre o que orientam alguns documentos oficiais e certos critérios de avaliação de determinadas instâncias oficiais. discursiva do tratamento dos gêneros, a orientação volta-se para uma interpretação do texto que permita, ao professor e ao aluno, estabelecer uma autêntica relação dialógica com os diferentes discursos.

Assim, se em relação ao tratamento metodológico dos gêneros em geral, constata-se uma boa distância entre as práticas escolares e as orientações oficiais ${ }^{4}$, em relação aos textos literários, há ainda uma condição específica hoje que contribui para a urgente necessidade de sua reinserção no cotidiano escolar. Desde a divulgação dos Parâmetros Curriculares Nacionais para o ensino básico (1998, 2000 e 2002), a orientação metodológica no ensino de Língua Portuguesa (LP) teve uma guinada importante não só para o estudo do texto de um modo geral, mas também para o ensino de literatura. Os textos literários passaram a conviver com textos de outras esferas em um mesmo grau de importância - o que acabou por facilitar, em muitas práticas escolares, a total ausência da literatura em sala de aula. Sob a perspectiva do ensino de literatura, portanto, há uma série de problemas cuja origem pode estar em um emprego inadequado dessa orientação metodológica. Atualmente, no campo do ensino de literatura, há uma vertente crítica (FISCHER et al., 2012; BELINTANE, 2011; ZILBERMAN, 2009; PAULINO e COSSON, 2009; RANGEL, 2005) que constata um ensino ou ainda tradicional - porque trabalha sobretudo com a história literária, os estilos, as épocas, em detrimento da leitura do texto propriamente -, ou pendente para o desaparecimento completo devido a certas práticas institucionais - avaliações oficiais e livros didáticos onde a formação de um leitor literário vem sendo cada vez menos exigida e trabalhada. ${ }^{5}$

Há ainda outro fator que contribui para a inexistência de formação específica do leitor literário: é uma espécie de confusão entre os objetivos do ensino de língua e os objetivos do ensino de literatura quando se trata do tipo de leitor que se quer formar. Em relação à metodologia de ensino de português, de um modo geral, Rangel (2005) dá uma boa pista para entendermos como determinados objetivos do ensino de língua não são os mesmos do ensino de literatura. $\mathrm{O}$ autor chama de "virada pragmática" as mudanças no ensino de língua desde a década de 80, quando a abordagem linguística passou a pautar as orientações metodológicas oficiais. Um dos objetivos básicos desse ensino é tornar o aluno proficiente no uso da língua oral e 
escrita. Rangel afirma que se essa qualidade é boa para formar um aluno que diante do texto "tem objetivos definidos e sabe avaliar, em cada situação de leitura, se dispõe de tempo e dos recursos necessários para atingi-los", sabe ainda reconhecer os gêneros, fazer previsões e interpretações, identificar o tema, reconhecer vozes etc. (RANGEL, 2005, p. 152), no entanto, não é a mais apropriada para orientar a formação do leitor literário, que não lê para, dado que o texto literário "abre uma perspectiva única de leitura" (RANGEL, 2005, p. 153). Na verdade, a leitura literária não "serve" a nenhum objetivo que não seja a leitura em si, sua polissemia intrínseca pede um leitor atento, nada mais, às vezes nem isso, podendo mesmo a experiência de leitura ser "vaga" - ao leitor, na literatura, é permitido flanar com a atenção solta de alguém que vai encontrando surpresas a cada página, ou não. Nada mais contrário, portanto, à noção de "proficiência no uso da língua", com toda a sua carga pragmática, necessária, sem dúvida, para inúmeros procedimentos de leitura e escrita, mas inadequada quando se trata de trabalhar com a formação do leitor literário.

Nesse debate, nossa contribuição procura direcionar-se metodologicamente para esclarecer alguns problemas específicos do ensino de literatura tanto da perspectiva da formação do leitor literário quanto do tratamento discursivo do texto literário.

Em primeiro lugar, para enfrentar a questão da confusão entre os objetivos do ensino de língua e os de literatura, é preciso ter clareza sobre o que Magda Soares chama de escolarização "inadequada da literatura". Para a autora

(...) os exercícios que, em geral, são propostos aos alunos sobre textos de literatura infantil não conduzem à análise do que é essencial neles, isto é, à percepção de sua literariedade, dos recursos de expressão, do uso estético da linguagem; centram-se nos conteúdos, e não na recriação que deles faz a literatura; voltam-se para as informações que os textos veiculam, não para o modo literário como as veiculam (SOARES, 2011, p. 43).

Segundo Soares (2011), algumas situações em que há uma escolarização inadequada da literatura ocorrem: quando se usa a literatura somente para fins gramaticais ou ortográficos, perde-se a interação lúdica, rítmica, imagética, polissêmica; quando se pede somente para o aluno localizar informações e 
6 Dentre outras, algumas publicações, mais recentes, com propostas metodológicas para abordar o texto literário são: Letramento literário: teoria e prática, de Rildo Cosson; Leitura do texto literário, de Ernani Terra; Leitura literária na sala de aula: propostas de aplicação, de Hiudéia Boberg e Rafaela Stopa. Uma proposta dialógica de ensino de literatura no ensino médio, tese de doutorado de William Cereja; Leitura de Literatura na escola de Maria Amélia Dalvi, Neide Rezende e Rita Jover-Faleiros (orgs.).

7 Capacidades de decodificação

- Compreender diferenças entre escrita e outras formas gráficas;

- Dominar as convenções gráficas;

- Conhecer o alfabeto;

- Compreender a natureza alfabética do nosso sistema de escrita;

- Dominar as relações entre grafemas e fonemas;

- Saber decodificar palavras e textos escritos;

- Saber ler reconhecendo globalmente as palavras;

- Ampliar a sacada do olhar para porções maiores de texto que meras palavras, desenvolvendo assim fluência e rapidez de leitura.

Capacidades de compreensão

- Ativação de conhecimentos prévios;

- Antecipação ou predição de conteúdos ou propriedades dos textos;

- Checagem de hipóteses;

- Localização e/ou cópia de informações;

- Comparação de informações;

- Generalização;

- Produção de inferências locais/globais (ROJO, 2004, p. 4-6). copiá-las; quando se permite a circulação de pseudotextos em sala de aula; trabalho com trechos soltos de narrativas, sem concatenação das partes, ou que desvirtuam sua estrutura. Essas são exatamente as mesmas situações descritas na Avaliação Diagnóstica feita pelo MEC (BRASIL, 2008) como correntes nas salas de aulas brasileiras quando se trata de uma metodologia inadequada de ensino de literatura. Parece haver certo consenso, então, em relação ao que é inadequado nesse campo.

Para haver uma escolarização adequada do ensino de literatura, há certamente várias metodologias. ${ }^{6}$ Aquela que propomos nesta pesquisa orienta-se a partir de determinadas capacidades de leitura. Para Rojo (2004, p. 4), essas capacidades - que se combinam dependendo das finalidades da leitura, dos "diferentes tipos de letramento, diferentes práticas de leitura, em diversas situações" - se subdividem em três grupos: de decodificação, de compreensão (estratégias) ${ }^{7}$ e de apreciação e réplica do leitor em relação ao texto (interpretação, interação):

- Recuperação do contexto de produção do texto;

- Definição de finalidades e metas da atividade de leitura;

- Percepção de relações de intertextualidade (no nível temático);

- Percepção de relações de interdiscursividade (no nível discursivo);

- Percepção de outras linguagens (imagens, som, imagens em movimento, diagramas, gráficos, mapas etc.) como elementos constitutivos dos sentidos dos textos e não somente da linguagem verbal escrita;

- Elaboração de apreciações estéticas e/ou afetivas;

- Elaboração de apreciações relativas a valores éticos e/ ou políticos (ROJO, 2004, p.6-7).

Embora as capacidades dos dois primeiros grupos também possam ser mobilizadas quando se leva em conta a formação do leitor literário na escola, para nós, a mobilização dessas últimas capacidades deve ser o norte em uma perspectiva discursiva por várias razões.

Como é possível observar pela composição das capacidades de interpretação e interação arroladas, a leitura, nesse âmbito, é compreendida como uma prática em que um discurso 
está em relação constante com outros discursos - que vieram antes dele, e/ou lhe são posteriores, ou estão imbricados nele. Nesse sentido, compreende-se que no discurso convergem múltiplos sentidos e julgamentos de valor que variam conforme o lugar social do autor, do leitor e de sua situação de interação. Essa é uma abordagem do conceito de acordo com a perspectiva bakhtiniana, dado que em sua teoria da literatura no conceito de discurso

(...) todos os termos de um texto vêm inseridos em múltiplas situações, em diferentes contextos linguísticos, históricos e culturais; assim, para Bakhtin, um texto possui sempre um sentido plural. (...) Por tudo isso, o sentido de uma obra literária é fruto de uma construção dialógica. (LOPES, 2003, p. 70).

A noção de "construção dialógica" do discurso é fundamental para trabalhar discursivamente qualquer texto, mas sobretudo os textos literários, dado que sua marca por excelência é a polissemia - os vários significados que concentrados na palavra literária certamente contribuem para a síntese de vozes discursivas que podem estar contidas numa metáfora, por exemplo (BAKHTIN, 1976). Com Bakhtin aprendemos a interrogar o texto literário procurando descobrir como realiza a produção de sentidos - e não como "representa" a realidade, ou como é construído, como propõem outras teorias.

No trabalho com literatura em sala de aula, se quisermos enfrentar os males da sua escolarização inadequada, é obrigatório, a nosso ver, passar aos professores conceitos como o de dialogismo, que contribui para abordar as diferentes camadas estilísticas e axiológicas próprias dos discursos artísticos em geral, não só do literário. Trabalhar didaticamente com a noção da "construção dialógica" do discurso literário, por exemplo, significa poder formar um leitor que percebe os matizes polissêmicos do texto, que pode construir interpretações sobre ele de acordo com sua visão de mundo e seus conhecimentos - de ordens variadas -, que pode fazer com certa segurança apreciações "estéticas e/ou afetivas" e elaborar "apreciações relativas a valores éticos e/ou políticos". Um leitor formado sob essa perspectiva compreende que não há uma única verdade soberana sobre os textos, mas inúmeras possibilidades de interpretação oferecidas pela obra: "Quem determina as 
possibilidades interpretativas é o texto. As leituras possíveis estão nele inscritas. Portanto, uma interpretação é válida por marcas, vestígios, indícios presentes na superfície textual." (FIORIN, 2009, p. 52)

Outro aspecto da teoria bakhtiniana, imbricado à construção dialógica de sentido, e que deve ser bem compreendido pelo professor que formará o leitor literário, trata-se da comunicação como fator central na linguagem:

O próprio ser do homem (exterior como interior) é uma comunicação profunda. Ser significa comunicar (...) O homem não possui um território interior soberano, ele se situa todo e sempre em uma fronteira: olhando para o seu interior; ele o olha nos olhos do outro ou através dos olhos do outro (BAKHTIN, 1981 apud LOPES, 2003, p. 79).

Esse aspecto contribui para entender como a produção discursiva tem sempre o outro a lhe orientar como um elemento presumido do discurso: o discurso presumido do ouvinte, do leitor sobre determinado texto, ideia etc. é parte constitutiva de qualquer produção discursiva. Entender isso contribui, dentre tantos aspectos importantes, para que o professor possa olhar para a produção literária, perceber nela as diferentes vozes discursivas, outro conceito basilar na teoria bakhtiniana do discurso, e consequentemente chamar a atenção sobre elas em suas análises em sala de aula. Dessa forma, será possível ao professor ter segurança e autonomia para perceber, por exemplo, o que Bakhtin revelou sobre a obra de Dostoiévski, mas que está no cerne de qualquer grande obra literária:

Dostoiévski tinha o dom genial de auscultar o diálogo de sua época, ou, em termos mais precisos, auscultar a sua época como um grande diálogo, de captar nela não só vozes isoladas mas antes de tudo as relações dialógicas entre as vozes, a interação dialógica entre elas. Ele auscultava também as vozes dominantes, reconhecidas e estridentes da época, ou seja, as ideias dominantes (oficiais e não oficiais), bem como vozes ainda fracas, ideias ainda não inteiramente manifestas, ideias latentes ainda não auscultadas por ninguém exceto por ele e ideias que apenas começavam a amadurecer, embriões de futuras concepções de mundo. (BAKHTIN, 1981, p. 75)

Compreender as vozes discursivas (dominantes, não dominantes e latentes) que compõem obras como Hamlet, Otelo, 
O retrato de Dorian Gray, Lavoura Arcaica, Memórias do Cárcere - para citar apenas alguns clássicos da literatura estrangeira e brasileira que compõem o acervo distribuído pelo PNBE/2013 - é parte do trabalho do professor sob uma perspectiva discursiva do ensino de literatura. Parte do seu trabalho também é poder construir juntamente com seus alunos uma interpretação segura das obras analisadas em sala.

Sob a perspectiva de uma análise axiológica, cerne da teoria bakhtiniana do discurso, é importante entender que a comunicação se dá por meio do enunciado concreto que compreende duas partes: a parte percebida ou realizada em palavras e a parte presumida - o horizonte espacial e ideacional compartilhado pelos falantes; sua característica distintiva é que estabelece uma miríade de conexões com o contexto extraverbal da vida (BAKHTIN; VOLOSHINOV, 1976). E aqui se entra, ainda, numa parte fundamental do trabalho metodológico de perspectiva bakhtiniana: a parte presumida do enunciado concreto engloba o que o teórico russo chama de "avaliações sociais básicas" que são parte de distintos grupos sociais - organizam seu comportamento e ações, já se fundiram aos objetos e fenômenos aos quais correspondem. Para o teórico russo, um julgamento de valor, parte das avaliações sociais básicas, muitas vezes pode nem fazer parte do conteúdo do discurso, antes disso, esse julgamento "determina a própria seleção do material verbal e a forma do todo verbal" (BAKHTIN, 1976, p. 7). A compreensão do conceito de enunciado concreto, portanto, contribui para que o professor perceba a questão da ideologia sob o ponto de vista bakhtiniano - tudo o que envolve a visão de mundo e sua escala de valor. Essa noção contribui muito para perceber os valores, positivos e negativos, que atravessam todos os discursos e os constituem como discursos pertencentes às mais diferentes vozes sociais. Compreender esse processo, na verdade, é uma boa oportunidade para que o professor não caia nas armadilhas de visões ingênuas que pregam, por exemplo, a "neutralidade" de determinados discursos. Com um bom domínio sobre a questão ideológica, como parte intrínseca de qualquer discurso, o professor vai poder contribuir para criar um olhar substancialmente crítico de seu aluno, $\mathrm{o}$ 
que, em tempos de uma cultura de massa avassaladora e tão presente no cotidiano de todas as classes, não é pouca coisa:

Retomando o título deste ensaio [Poesia e indiferença], diríamos simplesmente que, a contrapelo da indiferença, decorrente do ceticismo que compõe a base atual dos comportamentos sociais e políticos, nada mais extemporâneo do que a poesia, nada mais inadequado do que ela nesta época em que critérios como utilidade e eficácia impõem-se como determinantes dos valores de prestígio. E nada mais fecundo do que ela para embasar o exercício crítico e a perspectiva transformadora. (OSAKABE, 2005, p. 54)

\section{REFERÊNCIAS}

BAKHTIN, Mikhail. Problemas da poética de Dostoiévski. Tradução de Paulo Bezerra. Rio de Janeiro: Forense Universitária, 1981. . Marxismo e filosofia da linguagem. Tradução de Michel Lahud e Yara Frateschi Vieira com a colaboração de Lúcia Teixeira Wisnik e Carlos Henrique D. Chagas Cruz. 4. ed. São Paulo: Hucitec, 1988.

; VOLOSHINOV, V. N. “Discurso na vida e discurso na arte". Tradução para o português de Carlos Alberto Faraco e Cristovão Tezza, para uso didático, tomou como base a tradução inglesa de I. R. Titunik ("Discourse in life and discourse in art - concerning sociological poetics"), publicada em V. N. Voloshinov, Freudism, New York. Academic Press, 1976.

BELINTANE, Claudemir. A oralidade faz escrita na(s) infâncias(s): pesquisas e reflexões sobre a relação oralidade - escrita nos anos iniciais de escolarização. Tese (Livre Docência) - Faculdade de Educação/USP, 2011.

BERENBLUM, Andréa; PAIVA, Jane. Por uma política de formação de leitores. Brasília: Ministério da Educação, Secretaria de Educação Básica, 2006.

BOBERG, Hiudéia; STOPA, Rafaela. Leitura literária na sala de aula: propostas de aplicação. Curitiba: CRV, 2012.

BRASIL. Parâmetros Curriculares Nacionais: Terceiro e Quarto Ciclo do Ensino Fundamental - Brasília. MEC/SEF, 1998.

BRASIL. Parâmetros Curriculares Nacionais: Ensino Médio. Brasília: MEC/Semtec, 2000. 
BRASIL. PCN + ensino médio: orientações educacionais complementares aos Parâmetros Curriculares Nacionais. Volume Linguagens, códigos e suas tecnologias. Brasília: MEC/ SEMTEC, 2002.

BRASIL. Orientações curriculares do ensino médio. Linguagens, códigos e suas tecnologias / Secretaria de Educação Básica. - Brasília: Ministério da Educação, Secretaria de Educação Básica, 2006.

BRASIL. Programa Nacional Biblioteca da Escola (PNBE): leitura e bibliotecas nas escolas públicas brasileiras / Secretaria de Educação Básica, Coordenação-Geral de Materiais Didáticos; elaboração Andréa Berenblum e Jane Paiva. - Brasília: Ministério da Educação, 2008.

BRASIL. Ministério da Educação, Secretaria de Educação Básica. Guia de livros didáticos: PNLD 2013: letramento e alfabetização e língua portuguesa. - Brasília: 2012. 256 p.

CEREJA, William. Uma proposta dialógica de ensino de literatura no ensino médio. Tese (Doutorado) - LAEL/ Pontifícia Universidade Católica, 2004.

COSSON, Rildo. Letramento literário: teoria e prática. São Paulo: Contexto, 2009.

CUNHA, Dóris A. C. A estilística da enunciação para o estudo da prosa literária no ensino médio. In: BUNZEN, Clécio; MENDONÇA, Márcia (orgs.). Português no ensino médio e formação do professor. São Paulo: Parábola Editorial, 2006.

DALVI, Maria Amélia; REZENDE, Neide; JOVER-FALEIROS, Rita (orgs.). Leitura de Literatura na escola. São Paulo: Parábola Editorial, 2013.

FARACO, Carlos. Linguagem \& diálogo: as ideias linguísticas do círculo de Bakhtin. São Paulo: Parábola Editoria, 2009.

FIORIN, José Luiz. Leitura e dialogismo. In: RÖSING, Tânia M.K; ZILBERNAM, Regina (orgs.). Escola e leitura: velha crise, novas alternativas. São Paulo: Global, 2009. P. 41-59.

FISCHER, Luís Augusto; LUFT, Gabriela; FRIZON, Marcelo; LEITE, Guto; LUCENA, Karina; VIANNA, Carla; WELLER, Daniel. A Literatura no Exame Nacional do Ensino Médio (ENEM). Nonada Letras em Revista. Porto Alegre, ano 15, n. 18, p. 111-126, 2012. 
OLIVEIRA, Gabriela Rodella. O professor de português e a literatura. São Paulo: Alameda Editorial/FAPESP. 2014

OSAKABE, Haquira; FREDERICO, Enid Yatsuda. Literatura. Orientações curriculares do ensino médio. Brasília: MEC/ SEB/ DPPEM, 2004.

. Poesia e indiferença. In: Leituras literárias: discursos transitivos. Aparecida Paiva, Aracy Martins, Graça Paulino, Zélia Versiani (orgs.) Belo Horizonte: Ceale; Autêntica, 2005. P. 37-54.

PAULINO, Graça; COSSON, Rildo. Letramento literário: para viver a literatura dentro e fora da escola. In: RÖSING, Tânia M.K; ZILBERNAM, Regina (orgs.). Escola e leitura: velha crise, novas alternativas. São Paulo: Global, 2009. 61-79.

PINTO, Mayra. Alguns descompassos no ensino de literatura: documentos e práticas oficiais. Campinas: Remate de Males (IEL/UNICAMP), no prelo.

RANGEL, Egon de Oliveira. Literatura e livro didático no ensino médio: caminhos e ciladas na formação do leitor. In: Leituras literárias: discursos transitivos. Aparecida Paiva, Aracy Martins, Graça Paulino, Zélia Versiani (orgs.) Belo Horizonte: Ceale; Autêntica, 2005. P. 143-162.

ROJO, Roxane. Letramento e capacidades de leitura para a cidadania. São Paulo: SEE: CENP, 2004. Disponível em http:// deleste2.edunet.sp.gov.br/htpc2012/pc1_letramento.pdf. Acesso em 11.11.2013.

ROJO, Roxane. O texto como unidade e o gênero como objeto de ensino de Língua Portuguesa. In: L. C. Tavaglia (Org.) Encontro na linguagem - Estudos lingüísticos e literários. Uberlândia, MG: EDUFU, 2006, pp. 51-80.

SCHNEUWLY, Bernard et al. Gêneros orais e escritos na escola. Tradução e organização de Roxane Rojo e Glaís Sales Cordeiro. Campinas, Mercado de Letras, 2004.

SOARES, Magda. A escolarização da literatura infantil e juvenil. In: EVANGELISTA, Aracy; BRANDÃO, Heliana; MACHADO, Maria Zélia (orgs.). A escolarização da leitura literária. Belo Horizonte: Autêntica, 2011. P.17-48.

TERRA, Ernani. Leitura do texto literário. São Paulo: Contexto, 2014. 
ZILBERMAN, Regina. Que literatura para a escola? Que escola para a literatura? Revista do Programa de Pós-Graduação em Letras da Universidade de Passo Fundo - v. 5 - n. 1 - 9-20 - jan./jun. 2009. A escola e a leitura da literatura. In: RÖSING, Tânia M.K; ZILBERMAM, Regina (orgs.). Escola e leitura: velha crise, novas alternativas. São Paulo: Global, 2009a. P. 17-39. 


\section{Abstract \\ Some concepts of the bakhtinian dialogic theory of discourse and the literature teaching}

This article - part of the postdoctoral project $A$ Bakhtinian theoretical and methodological approach of the literary collection of the National Program School Library (PNBE)/2013 for high school - aims to show the relevance of some concepts of Bakhtin's theory of discourse for teaching literature. In working with literature in the classroom, if we want to face the evils of its inadequate schooling (SOARES, 2011), it is important to understand concepts such as dialogism, which helps to address the different stylistic and axiological layers of the artistic discourses in general, not only of the literary ones. Working didactically with the notion of "dialogic construction" of the literary discourse means to form readers able to notice the nuances of the polysemic text, who can build interpretations of it according to their world view and knowledge, who can make "aesthetic and / or affective" appreciations with confidence and develop "appreciations on ethical and /or political values" (ROJO, 2004). Under Bakhtin's perspective, it is understood that communication is done through the concrete utterance comprising two parts: the part perceived or performed on words and the assumed part - the spatial and ideational horizon shared by speakers; its distinctive feature is that it provides a myriad of connections with the extra verbal context of life (BAKHTIN, VOLOSHINOV, 1976). The understanding of the concept of concrete utterance contributes to the teacher perceives the question of ideology from the Bakhtinian point of view - everything that involves the worldview and its value scale. This notion allows us to see the positive and negative values that run through all the discourses and constitute them as discourses from different social voices.

Keywords: Literature teaching; Dialogism; Concrete utterance. 